\title{
Modeling Particle Loss in Ventilation Ducts
}

\author{
MARK R. SipPola ${ }^{1}$ and William W. NAZAROFF ${ }^{1,2, *}$ \\ ${ }^{1}$ Indoor Environment Department, Environmental Energy Technologies Division, Ernest \\ Orlando Lawrence Berkeley National Laboratory, Berkeley, CA 94720 USA \\ ${ }^{2}$ Department of Civil and Environmental Engineering, University of California, Berkeley, CA \\ 94720-1710 USA
}

\section{Abstract}

Empirical equations were developed and applied to predict losses of 0.01-100 $\mu \mathrm{m}$ airborne particles making a single pass through 120 different ventilation duct runs typical of those found in mid-sized office buildings. For all duct runs, losses were negligible for submicron particles and nearly complete for particles larger than $50 \mu \mathrm{m}$. The $50^{\text {th }}$ percentile cutpoint diameters were $15 \mu \mathrm{m}$ in supply runs and $25 \mu \mathrm{m}$ in return runs. Losses in supply duct runs were higher than in return duct runs, mostly because internal insulation was present in portions of supply duct runs, but absent from return duct runs. Single-pass equations for particle loss in duct runs were combined with models for predicting ventilation system filtration efficiency and particle deposition to indoor surfaces to evaluate the fates of particles of indoor and outdoor origin in an archetypal mechanically ventilated building. Results suggest that duct losses are a minor influence for determining indoor concentrations for most particle sizes. Losses in ducts were of a comparable magnitude to indoor surface losses for most particle sizes. For outdoor air drawn into an unfiltered ventilation system, most particles smaller than $1 \mu \mathrm{m}$ are exhausted from

\footnotetext{
* Address correspondence to: Prof. William W Nazaroff, Department of Civil and Environmental Engineering, 633 Davis Hall, University of California, Berkeley, CA 94720-1710 USA. Tel.: +1-510-642-1040. Fax: +1-510-642-7483. E-mail: nazaroff@ce.berkeley.edu
} 
the building. Large particles deposit within the building, mostly in supply ducts or on indoor surfaces. When filters are present, most particles are either filtered or exhausted. The fates of particles generated indoors follow similar trends as outdoor particles drawn into the building.

\section{Key words}

Aerosol, Deposition, Indoor air quality, Transport mechanisms, Ventilation

\section{Introduction}

Knowledge of depositional losses in ventilation ducts is useful for evaluating human exposures to particles within buildings and for predicting particle accumulation rates in ducts. Particle concentrations can be influenced by deposition in ducts as outdoor air is drawn into a building or as indoor air is recirculated through a ventilation system. Building remediation may be necessary following the release of a hazardous aerosol near, or within a building. The ability to predict the degree of deposition and the locations within ventilation ducts where hazardous aerosols deposit may improve the effectiveness of remediation and reduce the associated costs.

Models for predicting particle penetration through a series of straight tubes and bends have been proposed (Anand et al., 1993; Brockman, 2001). These were developed to predict penetration through aerosol sampling lines that are similar to ventilation duct runs, but much smaller. Wallin (1994) applied a model to predict accumulation rates of particle deposits in ducts; however, only $10 \mu \mathrm{m}$ particles were considered. These models are applicable only to round ventilation ducts and cannot reliably be applied to ducts with rectangular cross sections.

In this paper, empirical equations are combined with experimental data to predict particle deposition rates in ventilation ducts. Relative to prior work, advantages of these equations are that they may be applied to ducts of rectangular cross section and that they should provide good 
estimates of deposition rates to both steel and insulated duct surfaces. The equations reveal detailed information regarding deposition location. Losses are evaluated for the particle size range $0.01-100 \mu \mathrm{m}$. Single-pass losses are combined with predictions of filtration efficiencies and indoor loss rates to evaluate the fates of particles in an archetypal mechanically ventilated building. Fates of both outdoor and indoor particles are modeled for a building with no ventilation system filtration, and with $40 \%$ and $85 \%$ ASHRAE efficient filters.

\section{Methods}

\subsection{Simulated duct runs}

The study considered 60 supply and 60 return duct runs. These modeled runs were based on real ventilation systems in four university buildings. The duct runs represent the range of lengths in each building. Duct lengths, dimensions and airflow rates were read from as-built mechanical system drawings and confirmed by observation. Characteristics are summarized in Table 1. All ducts had rectangular cross-sections. All supply duct runs had some length that was internally insulated, and no return duct runs had any internal insulation.

\subsection{Definition of parameters}

The deposition velocity, $V_{d}$, of a particle to a duct surface is defined as

$$
V_{d}=\frac{J}{C_{a v e}}
$$

where $J$ is the time-averaged particle flux to the surface and $C_{a v e}$ is the time-averaged airborne particle concentration in the duct. Among other factors, deposition velocity depends on particle size and on the orientation and roughness of the deposition surface.

The fraction of particles penetrating a duct, $P_{d u c t}$, is defined by 


$$
P_{\text {duct }}=\frac{C_{\text {out }}}{C_{\text {in }}}
$$

where $C_{\text {out }}$ and $C_{\text {in }}$ are the flow-weighted average particle concentrations at the outlet and inlet of the duct, respectively. The fraction of particles lost to duct surfaces, $l_{\text {duct }}$, is

$$
l_{\text {duct }}=1-P_{\text {duct }}
$$

If the deposition velocity is determined as the area-weighted average over all interior duct surfaces (floor, wall and ceiling), then the penetration of that particle size through a straight duct section is related to the deposition velocity as follows:

$$
P_{\text {duct }}=\exp \left(\frac{-P L V_{d}}{A U_{\text {ave }}}\right)
$$

Here, $U_{\text {ave }}$ is the average air speed in the axial direction, $A$ is the cross sectional area of the duct, $L$ is the duct-section length and $P$ is the perimeter of the duct normal to the flow direction.

The dimensionless particle deposition velocity, $V_{d}^{+}$, is defined by normalizing the deposition velocity with the friction velocity, $u^{*}$ :

$$
V_{d}^{+}=\frac{V_{d}}{u^{*}}
$$

The friction velocity of a turbulent duct flow can be calculated by

$$
u^{*}=U_{\text {ave }} \sqrt{f / 2}
$$

where $f$ is the Fanning friction factor. For a fully developed turbulent flow in a smooth- or rough-walled duct, $f$ can be calculated using the following equation (White, 1986) 


$$
\frac{1}{\sqrt{f}}=-3.6 \log \left[\frac{6.9}{\operatorname{Re}}+\left(\frac{k}{3.7 D_{h}}\right)^{1.11}\right]
$$

Here, $k$ is the mean microscale roughness height of the rough wall and Re is the Reynolds number of the duct flow calculated by

$$
\operatorname{Re}=\frac{D_{h} U_{\text {ave }}}{v}
$$

where $v$ is the kinematic viscosity of air. The duct hydraulic diameter, $D_{h}$, is defined by this expression:

$$
D_{h}=\frac{4 A}{P}
$$

A dimensionless particle relaxation time, $\tau^{+}$, may be calculated for spherical particles in the Stokes flow regime as follows:

$$
\tau^{+}=\frac{C_{c} \rho_{p} d_{p}^{2} u^{*^{2}}}{18 \mu \nu}
$$

where $C_{c}$ is the slip correction factor, $\rho_{p}$ is the particle density, $d_{p}$ is the particle diameter and $\mu$ is the dynamic viscosity of air. The slip correction factor may be computed as

$$
C_{c}=1+\mathrm{Kn}\left[1.257+0.4 \exp \left(-\frac{1.1}{\mathrm{Kn}}\right)\right]
$$

where $\mathrm{Kn}$ is the Knudsen number:

$$
\mathrm{Kn}=\frac{2 \lambda}{d_{p}}
$$


Here, $\lambda$ is the mean free path of gas molecules, equal to $0.065 \mu \mathrm{m}$ at a temperature of $25^{\circ} \mathrm{C}$ and atmospheric pressure.

Particle deposition from turbulent flow depends on the Schmidt number, Sc, defined by

$$
\mathrm{Sc}=\frac{v}{D_{B}}
$$

The Brownian diffusivity, $D_{B}$, of a particle in air can be calculated by means of the StokesEinstein relation, corrected for slip:

$$
D_{B}=\frac{C_{C} k_{B} T}{3 \pi d_{p} \mu}
$$

where $k_{B}=1.38 \times 10^{-23} \mathrm{~J} \mathrm{~K}^{-1}$ is Boltzmann's constant and $T$ is the absolute temperature $(\mathrm{K})$.

\subsection{Empirical equations for predicting particle deposition in ventilation ducts}

Empirical equations for predicting deposition rates to surfaces in straight ducts and to Sconnectors at duct junctions were developed based on experimental data collected in our lab (Sippola, 2002). The equations are similar to published forms (Papavergos and Hedly, 1984; Kvasnak and Ahmadi, 1996), but are applied here for both steel and internally insulated duct surfaces. The general form of the equations for duct ceiling and wall surfaces are as follows:

$$
\begin{array}{ll}
V_{d}^{+}=k_{1} \mathrm{Sc}^{-2 / 3}+k_{2} \tau^{+^{k 4}} & \text { if } k_{1} \mathrm{Sc}^{-2 / 3}+k_{2} \tau^{+^{k 4}} \leq k_{3} \\
V_{d}^{+}=k_{3} & \text { if } k_{1} \mathrm{Sc}^{-2 / 3}+k_{2} \tau^{+^{k 4}}>k_{3}
\end{array}
$$

The value for $k_{1}$ depends on the Fanning friction factor (Kay and Nedderman, 1990):

$$
k_{1}=\sqrt{\frac{f}{2}}
$$


A value of 0.13 was selected for $k_{3}$ based on published data (Papavergos and Hedley, 1984) and confirmed by on our own experimental data.

Values of $k_{2}$ and $k_{4}$ were determined by power-law fits to experimental data at each surface and air speed. Particle deposition data were collected in our lab at air speeds of 2.2, 5.3 and $9.0 \mathrm{~m} \mathrm{~s}^{-1}$ in steel ducts and air speeds of 2.2, 5.3 and $8.8 \mathrm{~m} \mathrm{~s}^{-1}$ in insulated ducts.

Regressions were performed on data separately collected for the wall and ceiling of both steel and insulated ducts at each experimental air speed. Values of $k_{2}$ and $k_{4}$ are summarized for both steel and insulated duct surfaces in Table 2. In insulated ducts at an air speed of either 5.3 or 8.8 $\mathrm{m} \mathrm{s}^{-1}$, measured deposition rates at duct walls and ceilings were nearly the same. Consequently, for these air speeds in insulated ducts, a single regression was applied for wall and ceiling data.

To predict dimensionless deposition velocities to the floors of steel and insulated ducts, $V_{d, f}^{+}$, the following equation, which accounts for gravitational settling, was used

$$
V_{d, f}^{+}=V_{d, w}^{+}+g^{+} \tau^{+}
$$

Here, $V_{d, w}^{+}$is the deposition rate to an insulated wall as determined by equations (15) and (16) and $g^{+}$is the dimensionless gravitational acceleration calculated by the following equation, where $g=9.81 \mathrm{~m} \mathrm{~s}^{-2}$ is the gravitational acceleration:

$$
g^{+}=\frac{g v}{u^{* 2}}
$$

Equations (15)-(18) are strictly applicable to flows with friction velocities $\left(u^{*}\right)$ equal to those present in our lab experiments. An interpolation scheme was used to predict deposition rates for a broader range of conditions. Application of equations (15)-(18) to a general turbulent duct flow involves determining the friction velocity of the flow, determining the bounding 
deposition rates from equations (15)-(18) and interpolating from those values to the actual friction velocity.

Given duct dimensions and air speed, $u^{*}$ can be calculated by use of equation (6). For clean steel ducts, $f$ can be calculated by equation (7) with $k=0$. For the internally insulated ducts in our experiments, data showed that equation (7) yielded good estimates for $k=1700 \mu \mathrm{m}$.

Values of $V_{d}^{+}$at the three experimental friction velocities, $u_{1}^{*}, u_{2}^{*}$ and $u_{3}^{*}$, were calculated from equations (15)-(16). For steel ducts, the friction velocities $u_{1}^{*}, u_{2}^{*}$ and $u_{3}^{*}$ were respectively 12,27 and $45 \mathrm{~cm} \mathrm{~s}^{-1}$; for insulated ducts, they were 16,37 and $62 \mathrm{~cm} \mathrm{~s}^{-1}$, respectively. The dimensionless deposition velocity of a particle at the actual friction velocity was calculated by logarithmic interpolation using the following equations:

$$
\begin{array}{ll}
V_{d}^{+}=\operatorname{antilog}\left[\log \left(V_{d}^{+}\left(u_{2}^{*}\right)\right)-\frac{\left(u_{2}^{*}-u^{*}\right) \log \left(V_{d}^{+}\left(u_{2}^{*}\right) / V_{d}^{+}\left(u_{1}^{*}\right)\right)}{\left(u_{2}^{*}-u_{1}^{*}\right)}\right] \quad u^{*} \leq u_{2}^{*} \\
V_{d}^{+}=\operatorname{antilog}\left[\log \left(V_{d}^{+}\left(u_{2}^{*}\right)\right)+\frac{\left(u^{*}-u_{2}^{*}\right) \log \left(V_{d}^{+}\left(u_{3}^{*}\right) / V_{d}^{+}\left(u_{2}^{*}\right)\right)}{\left(u_{3}^{*}-u_{2}^{*}\right)}\right] \quad u^{*}>u_{2}^{*}
\end{array}
$$

In Figure 1(a) and 1(b), equations (15)-(18) are compared to experimental data collected for the different surfaces in steel and internally insulated ducts at an air speed of $5.3 \mathrm{~m} \mathrm{~s}^{-1}$. The good fit between the model equations and the data indicate that the functional forms of the empirical equations are appropriate.

\subsection{Predicting particle deposition at S-connectors and duct bends}

S-connectors are commonly present at junctions between two ducts to join and align the segments. S-connectors provide an internal ridge at which airborne particles may deposit by impaction. Our lab experiments showed that there was little difference among deposition rates at 
S-connectors located at duct floors, walls and ceilings. An equation for predicting particle deposition rates at S-connectors based on a specially defined particle Stokes number. Details of this equation are provided elsewhere (Sippola, 2002). A comparison of the equation to experimental data at an air speed of $5.3 \mathrm{~m} \mathrm{~s}^{-1}$ is given in Figure 1(c). While local deposition rates at S-connectors were found to be high, modeling suggests that S-connectors are relatively insignificant in influencing particle losses because they make up only a small fraction of the surface area of duct runs. Consequently, discussion of particle deposition in this paper focuses on straight ducts and duct bends.

Particle penetration through duct bends, $P_{\text {bend }}$, was calculated by means of the empirical model presented by McFarland et al. (1997). To apply this model, the particle Stokes number was calculated using the duct dimension (width or height) in the plane of the bend. The bend ratio, $R_{o}$, that appears in the model of McFarland et al. was difficult to determine for modeled duct bends; however, for the dimensions of ducts considered, the model was not sensitive to the value of $R_{o}$ in the range $1-5$. The range of bend ratios for nearly all ventilation duct bends is within this range; a value of 3 was used for all bend penetration calculations. A comparison of this model to experimental data of particle deposition in duct bends collected in our lab indicates good agreement (see Figure 1(d)).

\subsection{Particle losses in a single pass through duct runs}

Supply ducts runs generally begin with a large duct section near the outdoor air intake that branches into a series of successively smaller duct generations. Return runs begin with small duct generations that combine into successively larger generations. Penetration of particles in the size range $0.01-100 \mu \mathrm{m}$ through each duct generation was calculated independently. A new duct generation was defined to occur whenever one of the following characteristics 
changed: duct width, duct height, air speed, insulation status, or orientation. Air speeds were assumed to be constant in each duct generation.

Penetration through an entire duct run, $P_{\text {total }}$, was calculated by multiplying the calculated penetrations for all duct generations and bends in the duct run as follows:

$$
P_{\text {total }}=\prod_{i=1}^{n_{d}} P_{d u c t, i} \prod_{j=1}^{n_{b}} P_{\text {bend }, j}
$$

Here $n_{d}$ is the total number of duct generations and $n_{b}$ is the total number of bends.

For a given particle size, penetration through a straight duct generation was calculated by

$$
P_{\text {duct }, i}=P_{\text {ceiling }, i} P_{\text {wall }, i} P_{\text {floor }, i} P_{S, i}
$$

Here, $P_{\text {ceiling }, i}, P_{\text {wall }, i}, P_{\text {floor }, i}$ and $P_{S, i}$ are the penetrations through a straight duct generation owing to deposition that occurs only at the duct ceiling, wall, floor or S-connectors, respectively. For a straight duct generation, single-surface penetrations were calculated by equation (4). To apply this equation to a specific surface, $V_{d}$ was taken as the deposition velocity for the specific surface and the perimeter, $P$, was taken as the length contribution to the perimeter of the surface under consideration. The fraction of particles lost to a given surface in a straight duct generation was calculated by multiplying the total fraction of particles lost in the duct generation by the ratio of the single-surface loss rate to the total loss rate in that duct generation.

The fractions of total losses in an entire duct run owing to deposition on duct ceilings, duct walls, duct floors, duct bends and S-connectors at duct junctions were determined in each single-pass particle loss calculation. Similarly, the fractions of total losses owing to deposition in different classes of duct generations were calculated for the range of particle sizes. Duct generations were classified according to duct size, orientation and insulation status. Thus, eight classes of straight duct generations were defined: small-horizontal-steel, small-vertical-steel, 
small-horizontal-insulated, small-vertical-insulated, large-horizontal-steel, large-vertical-steel, large-horizontal-insulated and large-vertical-insulated. Ducts were classified as small if $D_{h} \leq 0.4$ $\mathrm{m}$ and large if $D_{h}>0.4 \mathrm{~m}$. Duct bends were classified as either large bends or small bends, according to whether the appropriate bend dimension was larger or smaller than $0.4 \mathrm{~m}$.

It was found that fractional losses for a single pass through most duct runs were negligible for submicron particles and close to one for particle larger than about $50 \mu \mathrm{m}$. Through the size range 1-50 $\mu \mathrm{m}$, the fraction of particles lost increased monotonically with particle diameter from $\sim$ zero to $\sim$ one for each duct run. The cut-point particle diameter for a duct run was defined as the diameter for which half of the particles were lost (and half penetrated) in a single pass. Supply runs were ranked in order of decreasing cut-point diameter. The ten supply runs with the smallest cut-point diameters were characterized as high-loss supply ducts and the ten with the largest cut-point diameters were characterized as low-loss supply ducts. The fraction of total losses onto different surfaces was determined as an average for the high-loss supply ducts. Similarly, the fraction of total losses resulting from deposition within each of the ten duct generation classes (eight straight duct classes and two bend classes) was calculated as an average for all high-loss supply ducts. The same calculations were carried out for low-loss supply ducts. The same ranking scheme and averaging system was also applied to return runs.

\subsection{Particle fates in a building}

Single-pass particle losses in duct runs were combined with empirical models for ventilation system filtration and deposition to indoor surfaces to evaluate the fates of particles in an archetypal mechanically ventilated building. Outdoor particles drawn into a building through the ventilation system and particles generated indoors were considered separately. A schematic of the model used to predict particle fates in the building is shown in Figure 2. The indoor 
volume, $V$, was treated as a well-mixed space and air entered and exited the building only via the ventilation system. In the figure, flow rates are labeled in relation to the total air supply rate to the building, $Q_{s}$. The fraction of return air from the building that is recirculated is $R$. The fraction of supplied air bypassing filtration is $F_{b}$. Five particle fates were considered: filtration, deposition to supply ducts, deposition to indoor surfaces, deposition to return ducts and leaving the building in exhaust air. Isothermal conditions were assumed and particle resuspension, coagulation and phase change were ignored. For all model applications, the supply air exchange rate was set equal to $5 \mathrm{~h}^{-1}$ and $R=0.8$, giving an outdoor air exchange rate of $1 \mathrm{~h}^{-1}$, typical for an occupied, mechanically ventilated building.

Two types of filters common in commercial ventilation systems were considered, respectively with $40 \%$ and $85 \%$ ASHRAE dust spot average efficiencies. Filtration efficiency curves were generated by a combination of theory and fitting to experimental data using the method described in Riley et al. (2002). Deposition to indoor surfaces was characterized by an indoor loss-rate coefficient, $\beta$, assessed using the combination of theory and empiricism described by Riley et al. (2002).

Using this combination of models, the fates of two types of particles were evaluated: those drawn in through the outdoor air intake and those generated indoors. Examples with lowloss and high-loss ducts are presented to illustrate the expected range of importance of deposition in ventilation ducts. When considering high-loss duct runs, the single-pass losses that were used as model inputs were those with the $90^{\text {th }}$ percentile cut-point diameter for supply and return ducts. For low-loss duct modeling scenarios, supply and return losses in duct runs were set equal to the losses of duct runs with the $10^{\text {th }}$ percentile cut-point diameter. 
Fractional fates of indoor and outdoor particles were determined for six scenarios. Ventilation systems with no filters, 40\% ASHRAE filters and 85\% ASHRAE filters were considered, each with either low-loss or high-loss duct runs. When the fractional fates of particles generated indoors were considered, a particle emissions profile was assumed and the generated aerosol was instantaneously mixed throughout the indoor space.

\section{Results}

\subsection{Particle losses in a single pass through supply and return ducts}

Table 1 summarizes the $10^{\text {th }}, 50^{\text {th }}$ and $90^{\text {th }}$ percentile cut-point diameters for return and supply duct runs. Figure 3 shows predicted single-pass particle losses for the modeled return and supply duct runs with the $10^{\text {th }}, 50^{\text {th }}$ and $90^{\text {th }}$ percentile cut-point diameters.

The average characteristics of the ten low-loss and ten high-loss return and supply duct runs are summarized in Table 3. For particles that deposit in a duct run, fates considered are deposition to vertical duct walls, to horizontal duct floors, to horizontal duct ceilings, to duct bends or to S-connectors at duct junctions. Figure 4 shows the fraction of total losses resulting from deposition at each of these locations for particle sizes in the range $0.01-100 \mu \mathrm{m}$. This figure shows the average for the ten low-loss and high-loss return and supply duct runs. In these plots, the fraction of the total losses for a certain particle size attributable to a given surface is indicated by the distance between the line for that surface and the next lowest line. The values in parentheses provide the percentages of the total straight duct surface area associated with each surface type. Figure 5 shows the fraction of total losses occurring in different classes of return and supply ducts. The value in parentheses after each straight duct label is the percentage of the total duct surface area associated with that duct class. The value after each bend label is the percentage of the total number of bends in that bend class. In cases where there is no loss 
contribution from a class of ducts, it is because no duct generations of that class existed in the runs considered. For example, no return ducts had any internal insulation and no vertical return duct had $D_{h} \leq 0.4 \mathrm{~m}$; consequently, only three straight duct classes are shown in Figure 5(a).

\subsection{Particle fates in a building}

For particles drawn into the building from outdoors, the fates of particles in the size range 0.01-100 $\mu \mathrm{m}$ are shown in Figure 6 for both low-loss and high-loss ducts. In Figure 6(a), for a building with no filtration, the fates considered are deposition in supply ducts, deposition to indoor surfaces, deposition in return ducts and exiting the building by exhaust. Figures 6(b) and 6(c) show results for buildings with 40\% and 85\% ASHRAE filters, respectively. The fractional fates of particles released indoors are illustrated in Figure 7 for both low-loss and high-loss ducts. Figure 7(a) shows the fractional fates of particles released in the building with an unfiltered ventilation system. Figures 7(b) and 7(c) show fractional fates of particle released indoors in buildings with $40 \%$ and $85 \%$ ASHRAE filters, respectively.

\section{Discussion}

\subsection{Particle losses in a single pass through supply and return ducts}

Figure 3(a) shows that particle losses resulting from a single pass through return ducts are negligible for particles less than $1 \mu \mathrm{m}$ and nearly complete for particles larger than $50 \mu \mathrm{m}$. Predicted losses in supply duct runs in Figure 3(b) show a similar shape, but with higher losses for particle sizes in the range 1-50 $\mu \mathrm{m}$. Differences among duct runs are therefore most important for determining particle losses in this intermediate size range. For example, $58 \%$ of 10 $\mu \mathrm{m}$ particles traveling through the supply duct run with the $90^{\text {th }}$ percentile cut-point diameter are predicted to deposit in the duct run, but only $12 \%$ are expected to deposit in the duct run with the 
$10^{\text {th }}$ percentile cut-point diameter. On the other hand, less than $0.2 \%$ of $0.1 \mu \mathrm{m}$ particles are predicted to deposit regardless of whether the duct run has the $10^{\text {th }}$ or $90^{\text {th }}$ percentile cut-point diameter. Factors contributing to higher losses in supply duct runs include the presence of internal insulation, more bends, and longer duct runs.

In Table 3, duct runs with high particle losses are seen to have longer lengths, longer residence times, more bends and more total surface area than the average duct run, as expected. Conversely, the low-loss duct runs, on average, have shorter lengths, shorter residence times, fewer bends and less surface area than the average duct run. Low-loss ducts also had less horizontal floor surface area and less surface area associated with small ducts than the average duct. An additional trend apparent in Table 3 is that of increasing particle loss with increasing insulated surface area in supply ducts. Horizontal floor surface area and insulated surface are important for determining particle losses because deposition rates to these surfaces are high. Small ducts are potentially important in determining particle losses because they have higher surface-area-to-volume ratios than larger ducts.

Figure 4(a) illustrates that there is little difference among loss locations between the lowloss and high-loss return ducts. For very small particles, diffusion controls deposition rates and so losses to all three orientations of duct surfaces contribute significantly to the total. An important particle size range to consider is $1-30 \mu \mathrm{m}$. This size range encompasses a variety of biological particles that are of concern and losses of particles of this size in ducts are expected to be significant. In return ducts, losses of 1-30 $\mu$ m particles result mainly from deposition to duct floors, but deposition in bends and to vertical duct walls also contribute to losses. Duct bends are slightly more important in determining losses in low-loss duct runs compared to high-loss duct runs, even though these runs had, on average, fewer bends. The bends are more important 
in low-loss ducts because other surfaces play a less significant role in determining losses relative to high-loss ducts.

Figure 4(b) shows that, for most particle sizes, losses to all duct surfaces were important in supply duct runs. For very small particles, the patterns of fractional losses in supply ducts are similar to those for return duct runs. For larger particles, duct walls and ceilings played a more prominent role in determining losses in the insulated supply duct runs than in the return duct runs with no insulation. Deposition to duct floors and bends made a smaller contribution to the total loss in supply ducts. This is mainly the result of the large increase in predicted deposition velocities to insulated duct walls and ceilings in supply ducts compared to steel walls and ceilings in return ducts.

The importance of horizontal duct losses in determining total losses in return ducts is illustrated in Figure 5(a). Horizontal duct generations are predicted to dominate losses for all but the largest particles in both low-loss and high-loss return ducts. The importance of small horizontal ducts increases in importance from low-loss to high-loss ducts. In the high-loss return ducts, $64 \%$ of the $10 \mu \mathrm{m}$ particles that deposit do so to surfaces in small ducts even though these surfaces constitute only $15 \%$ of the total surface area in the duct runs. Deposition in small bends is predicted to contribute more to total losses in bends than deposition in large bends, especially in high-loss ducts. Part of the reason is that smaller bend dimensions lead to higher deposition rates. Another factor is that return duct runs begin with small ducts that increase in size as they join with other ducts. Thus, ducts and bends with smaller dimensions are encountered first in a single pass through a return duct run. When particles are lost in these smaller ducts and bends, there are fewer particles left in the airstream to deposit downstream. In Figure 5(b), losses to insulated ducts are seen to be the major contributor to total losses for most particle sizes in 
supply duct runs. This was especially true in the high-loss supply duct runs where only a small fraction of the total deposit occurred at steel surfaces for particles larger than $0.5 \mu \mathrm{m}$. When losses are highest, they are mostly attributable to deposition in insulated duct generations. Vertical ducts play a larger role in determining particle losses when they are insulated, as in the supply ducts, compared to when they are not insulated, as in the return ducts. In high-loss ducts, losses in bends are predicted to be a very small fraction of the total particle loss for particles smaller than $10 \mu \mathrm{m}$.

\subsection{Particle fates in a building}

Consider the fates of outdoor particles drawn into a building via an unfiltered ventilation system. Figure 6(a) shows that the majority of submicron particles are exhausted from the building. Most particles larger than $1 \mu \mathrm{m}$ are predicted to deposit within the building. For a building with low-loss ducts, a large fraction of super-micron particles are predicted to deposit to indoor surfaces and deposition in supply ducts is an important fate only for particles larger than 5 $\mu \mathrm{m}$. The maximum percentage of particles depositing in low-loss return ducts is $3 \%$ for $12 \mu \mathrm{m}$ particles. If ducts have high losses, deposition in supply ducts is expected to be a significant fate for particles as small as $1 \mu \mathrm{m}$. For the case in which $40 \%$ or $85 \%$ ASHRAE filters are installed in the ventilation system supply ducts, Figures 6(b) and 6(c) show a large decrease in indoor surface deposition and duct deposition as a particle fate compared to the unfiltered case.

For particles released inside a building with unfiltered ventilation ducts, Figure 7(a) shows that their predicted fates follow similar general trends as the outdoor particles considered in Figure 6(a). Most submicron particles are exhausted and most large particles deposit within the building. The main differences between the fates of particles originating outdoors and indoors are the deposition locations of large particles. Figure 7(b) shows the fates of particles 
released in a building with $40 \%$ ASHRAE filters. In this case, deposition to indoor surfaces and ducts remains an important fate for large particles, and even for particles as small as $1 \mu \mathrm{m}$. For particles smaller than $4 \mu \mathrm{m}$, deposition in high-loss ducts is a fate comparable in magnitude to indoor surface deposition. For 1-30 $\mu \mathrm{m}$ particles, duct deposition may be an important fate. For example, $25 \%$ of $13 \mu \mathrm{m}$ particles released indoors, are predicted to deposit in high-loss ducts. Figure 7(c), shows that improving filtration from 40\% AHSRAE filters to $85 \%$ ASHRAE filters has little influence on the fate of indoor particles larger than $4 \mu \mathrm{m}$.

\section{Conclusions}

Empirical models for predicting deposition rates were applied to predict particle losses during the single pass of an aerosol through 60 supply duct runs and 60 return duct runs chosen from four university buildings. In general, fractional duct deposition was negligible for particles smaller than $1 \mu \mathrm{m}$ and complete for particles larger than $50 \mu \mathrm{m}$. Depositional losses were higher in supply runs than in return runs, mostly because of insulation in supply ducts. On average, losses were higher in duct runs that possess a greater-than-average value of one or more of these attributes: length, insulated surface area, small-duct surface area and number of bends.

Considering the particle diameter range 1-30 $\mu \mathrm{m}$, losses in return ducts are dominated by deposition to the floors of horizontal ducts. In uninsulated ducts, losses in vertical sections are very small compared to losses in horizontal sections. When insulation is present, as in supply duct runs, losses to vertical surfaces are a more significant contributor to total particle losses, but losses in horizontal duct generations remain the most important for determining overall loss.

The fates of indoor and outdoor particles in an archetypal mechanically ventilated building were modeled. Losses in ducts are predicted to play a small role in influencing indoor concentrations of outdoor particles. The importance of supply-duct deposition as a fate of 
outdoor particles is diminished when filtration is present. For 1-30 $\mu \mathrm{m}$ particles generated inside a building with no filtration, a significant fraction may deposit in both supply and return ducts. When released within a building with $40 \%$ ASHRAE filters, a larger fraction of particles larger than $1 \mu \mathrm{m}$ are predicted to deposit in ventilation ducts compared to particles drawn in from outdoors. Deposition in return ducts is a more important fate of particles released indoors than for outdoor particles. A significant percentage (up to $25 \%$ ) of 1-30 $\mu \mathrm{m}$ particles generated indoors may deposit in ventilation ducts, even when relatively efficient $85 \%$ ASHRAE filters are installed. In addition to providing information useful for evaluating particle exposures, the modeling results have implications for ventilation system design and maintenance and for building remediation after the release of a hazardous aerosol.

\section{Acknowledgements}

This work was supported by the Office of Nonproliferation Research and Engineering, Chemical and Biological National Security Program, of the National Nuclear Security Administration, U.S. Department of Energy under Contract No. DE-AC03-76SF00098.

\section{References}

Anand, N.K., McFarland, A.R., Wong, F.S. and Kocmoud, C.J., 1993. DEPOSITION: Software to calculate particle penetration through aerosol transport systems. Report NUREG/GR0006, Nuclear Regulatory Commission, Washington DC.

Brockman, J.E., 2001. Sampling and transport of aerosols. In: Baron, P.A. and Willeke, K. (Eds.), Aerosol Measurement: Principles, Techniques and Applications, $2^{\text {nd }}$ edition, Wiley, New York. 
Kay, J.M. and Nedderman, R.M., 1990. Fluid Mechanics and Transfer Processes, Cambridge University Press, New York.

Kvasnak, W. and Ahmadi, G., 1996. Deposition of ellipsoidal particles in turbulent duct flows. Chemical Engineering Science, 51, 5137-5148.

McFarland, A.R., Gong, H., Muyshondt, A., Wente, W.B. and Anand, N.K., 1997. Aerosol deposition in bends with turbulent flow. Environmental Science and Technology, 31, 33713377.

Papavergos, P.G. and Hedley, A.B., 1984. Particle deposition behaviour from turbulent flows. Chemical Engineering Research and Design, 62, 275-295.

Riley, W.J., McKone, T.E., Lai, A.C.K. and Nazaroff, W.W., 2002. Indoor particulate matter of outdoor origin: Importance of size dependent removal mechanisms. Environmental Science and Technology, 36, 200-207, 1868.

Sippola, M.R., 2002. Particle Deposition in Ventilation Ducts. Ph.D. Dissertation, University of California, Berkeley.

Wallin, O., 1994. Computer Simulation of Particle Deposition in Ventilating Duct Systems.

Ph.D. Dissertation, Royal Institute of Technology, Stockholm, Sweden.

White, F.M., 1986. Fluid Mechanics, $2^{\text {nd }}$ Edition. McGraw-Hill, New York.

\section{Figure Captions}

Figure 1. Comparison of empirical models to data collected in (a) straight steel ducts, (b) straight insulated ducts, (c) S-connectors and (d) steel duct bends with $U_{\text {ave }}=5.3$ $\mathrm{m} \mathrm{s}^{-1}$. 
Figure 2. Schematic diagram for analysis of particle fate in a mechanically ventilated building. The block arrows indicate airflow paths; small arrows show potential particle fates.

Figure 3. Predicted fractional losses for a single pass through (a) return duct runs and (b) supply duct runs.

Figure 4. Fraction of total losses occurring at different duct surfaces in (a) return duct runs and (b) supply duct runs with both low and high particle losses.

Figure 5. Fraction of total losses occurring in different duct generation classes in (a) return duct runs and (b) supply duct runs with both low and high particle losses.

Figure 6. Predicted fractional fates of outdoor particles drawn into an air intake with (a) no filters, (b) 40\% ASHRAE filters, and (c) 85\% ASHRAE filters for both low-loss and high-loss ducts.

Figure 7. Predicted fractional fates of particles released in a building with (a) no filters, (b) 40\% ASHRAE filters, and (c) 85\% ASHRAE filters for both low-loss and highloss ducts. 
Table 1 Characteristics of duct runs with values for the $10^{\text {th }}, 50^{\text {th }}$ and $90^{\text {th }}$ percentile cut-point diameters for a single pass of an aerosol. ${ }^{\mathrm{a}}$

\begin{tabular}{|c|c|c|}
\hline Parameter & $\begin{array}{c}\text { Return } \\
\text { duct runs }\end{array}$ & $\begin{array}{c}\text { Supply } \\
\text { duct runs }\end{array}$ \\
\hline length $(\mathrm{m})$ & $48(22-94)$ & $55(25-106)$ \\
residence time $(\mathrm{sec})$ & $9.7(4-18)$ & $10.7(4-20)$ \\
insulated length $(\%)$ & 0 & $52(20-90)$ \\
number of bends $(-)$ & $5.1(3-9)$ & $6.2(4-12)$ \\
$10^{\text {th }}$ percentile cut-point diameter $(\mu \mathrm{m})$ & 37 & 25 \\
$50^{\text {th }}$ percentile cut-point diameter $(\mu \mathrm{m})$ & 25 & 15 \\
$90^{\text {th }}$ percentile cut-point diameter $(\mu \mathrm{m})$ & 17 & 9 \\
\hline
\end{tabular}

${ }^{\mathrm{a}}$ Reported values are averages for 60 supply or 60 return duct runs with the range in parentheses.

Table 2 Values of $k_{2}$ and $k_{4}$ for use in equations (15) and (16) for the three experimental friction velocities in steel and insulated ducts.

\begin{tabular}{|c|c|c|c|c|c|c|}
\hline \multirow[b]{2}{*}{$\begin{array}{c}\text { Duct } \\
\text { material }\end{array}$} & \multirow[b]{2}{*}{$\begin{array}{c}\text { Air } \\
\text { speed, } \\
U_{\text {ave }}\left(\mathrm{m} \mathrm{s}^{-1}\right)\end{array}$} & \multirow[b]{2}{*}{$\begin{array}{l}\text { Friction } \\
\text { velocity } \\
\left(\mathrm{cm} \mathrm{s}^{-1}\right)\end{array}$} & \multicolumn{2}{|c|}{ Duct ceiling } & \multicolumn{2}{|c|}{ Duct wall } \\
\hline & & & $\begin{array}{l}k_{2} \\
(-)\end{array}$ & $\begin{array}{l}\boldsymbol{k}_{4} \\
(-)\end{array}$ & $\begin{array}{l}k_{2} \\
(-)\end{array}$ & $\begin{array}{l}k_{4} \\
(-)\end{array}$ \\
\hline \multirow{3}{*}{ steel } & 2.2 & $u_{1}{ }^{*}=12$ & $1.2 \times 10^{-4}$ & 0.64 & $2.6 \times 10^{-3}$ & 1.01 \\
\hline & 5.3 & $u_{2}{ }^{*}=27$ & $7.7 \times 10^{-5}$ & 0.74 & $1.1 \times 10^{-3}$ & 1.13 \\
\hline & 9.0 & $u_{3}{ }^{*}=45$ & $1.8 \times 10^{-4}$ & 1.10 & $8.1 \times 10^{-4}$ & 1.40 \\
\hline \multirow{3}{*}{ insulated } & 2.2 & $u_{1}^{*}=16$ & $6.7 \times 10^{-3}$ & 0.57 & $2.6 \times 10^{-3}$ & 0.77 \\
\hline & 5.3 & $u_{2}{ }^{*}=37$ & 0.019 & 0.74 & 0.019 & 0.74 \\
\hline & 8.8 & $u_{3}{ }^{*}=62$ & 0.014 & 0.71 & 0.014 & 0.71 \\
\hline
\end{tabular}

Table 3 Characteristics of low-loss and high-loss return and supply duct runs compared to the average of all return duct runs and all supply duct runs.

\begin{tabular}{|c|c|c|c|c|c|c|}
\hline & \multicolumn{3}{|c|}{ Return duct runs } & \multicolumn{3}{c|}{ Supply duct runs } \\
\cline { 2 - 6 } Parameter & $\begin{array}{c}\text { Average } \\
\text { of 10 } \\
\text { low-loss } \\
\text { duct runs }\end{array}$ & $\begin{array}{c}\text { Average } \\
\text { of all 60 } \\
\text { return } \\
\text { duct runs }\end{array}$ & $\begin{array}{c}\text { Average } \\
\text { of 10 } \\
\text { high-loss } \\
\text { duct runs }\end{array}$ & $\begin{array}{c}\text { Average } \\
\text { of 10 } \\
\text { low-loss } \\
\text { duct runs }\end{array}$ & $\begin{array}{c}\text { Average } \\
\text { of all 60 } \\
\text { supply } \\
\text { duct runs }\end{array}$ & $\begin{array}{c}\text { Average } \\
\text { of 10 } \\
\text { high-loss } \\
\text { duct runs }\end{array}$ \\
\hline length (m) & 29 & 48 & 63 & 38 & 55 & 70 \\
residence time (s) & 5.6 & 9.7 & 14.1 & 7.7 & 10.7 & 12.0 \\
number of bends (-) & 3.6 & 5.1 & 5.8 & 4.4 & 6.2 & 8.0 \\
total surface area (m) & 97 & 169 & 199 & 152 & 211 & 315 \\
wall surface area (\%) & 72 & 62 & 62 & 60 & 60 & 58 \\
floor surface area (\%) & 14 & 19 & 19 & 20 & 20 & 21 \\
ceiling surface area (\%) & 14 & 19 & 19 & 20 & 20 & 21 \\
Insulated area (\%) & 0 & 0 & 0 & 66 & 73 & 89 \\
steel area (\%) & 100 & 100 & 100 & 34 & 27 & 11 \\
large duct area (\%) & 94 & 89 & 85 & 94 & 89 & 87 \\
small duct area (\%) & 6 & 11 & 15 & 6 & 11 & 13 \\
\hline
\end{tabular}

${ }^{\mathrm{a}}$ Small ducts are defined as having $D_{h} \leq 0.4 \mathrm{~m}$; for large ducts, $D_{h}>0.4 \mathrm{~m}$. 
(a) straight steel ducts

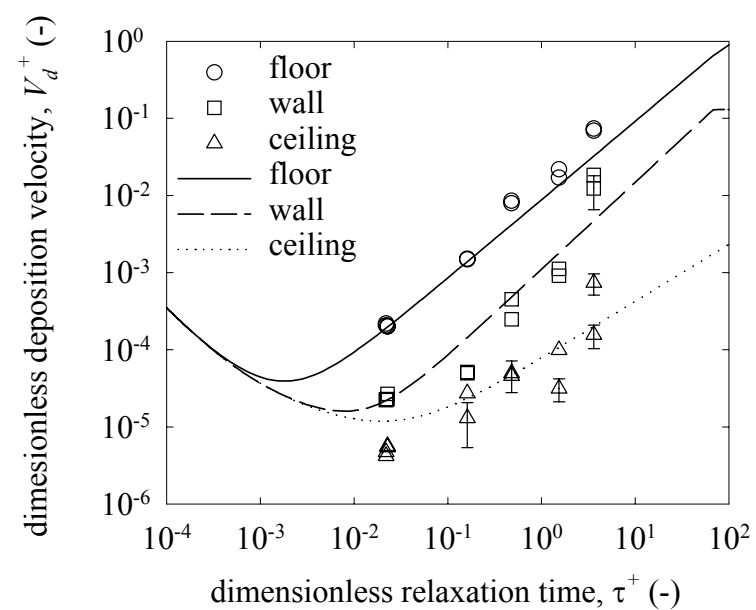

(c) S-connectors

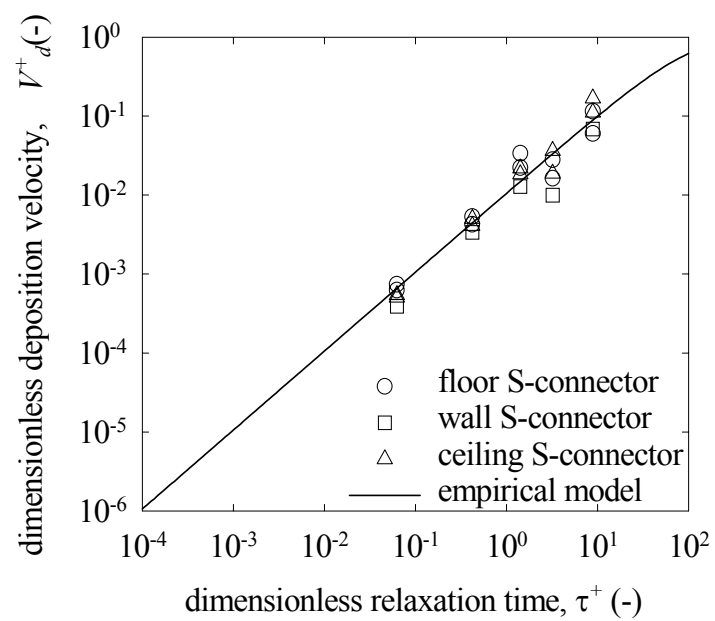

(b) straight insulated ducts

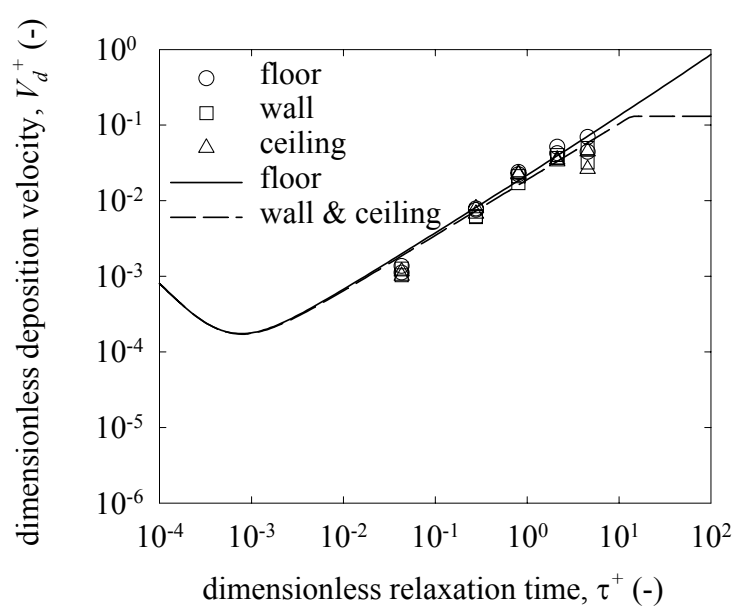

(d) steel duct bends

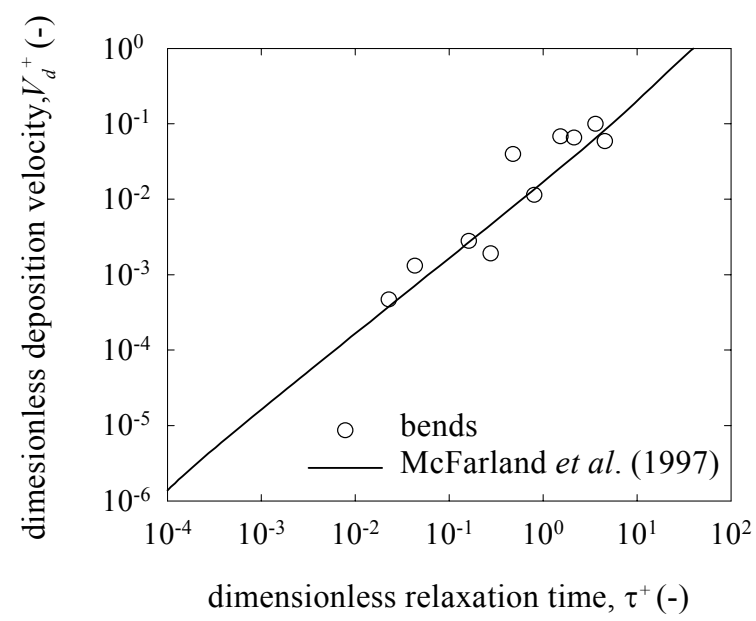

Figure 1 Comparison of empirical models to data collected in (a) straight steel ducts, (b) straight insulated ducts, (c) S-connectors and (d) steel duct bends with $U_{\text {ave }}=5.3 \mathrm{~m} \mathrm{~s}^{-1}$. 


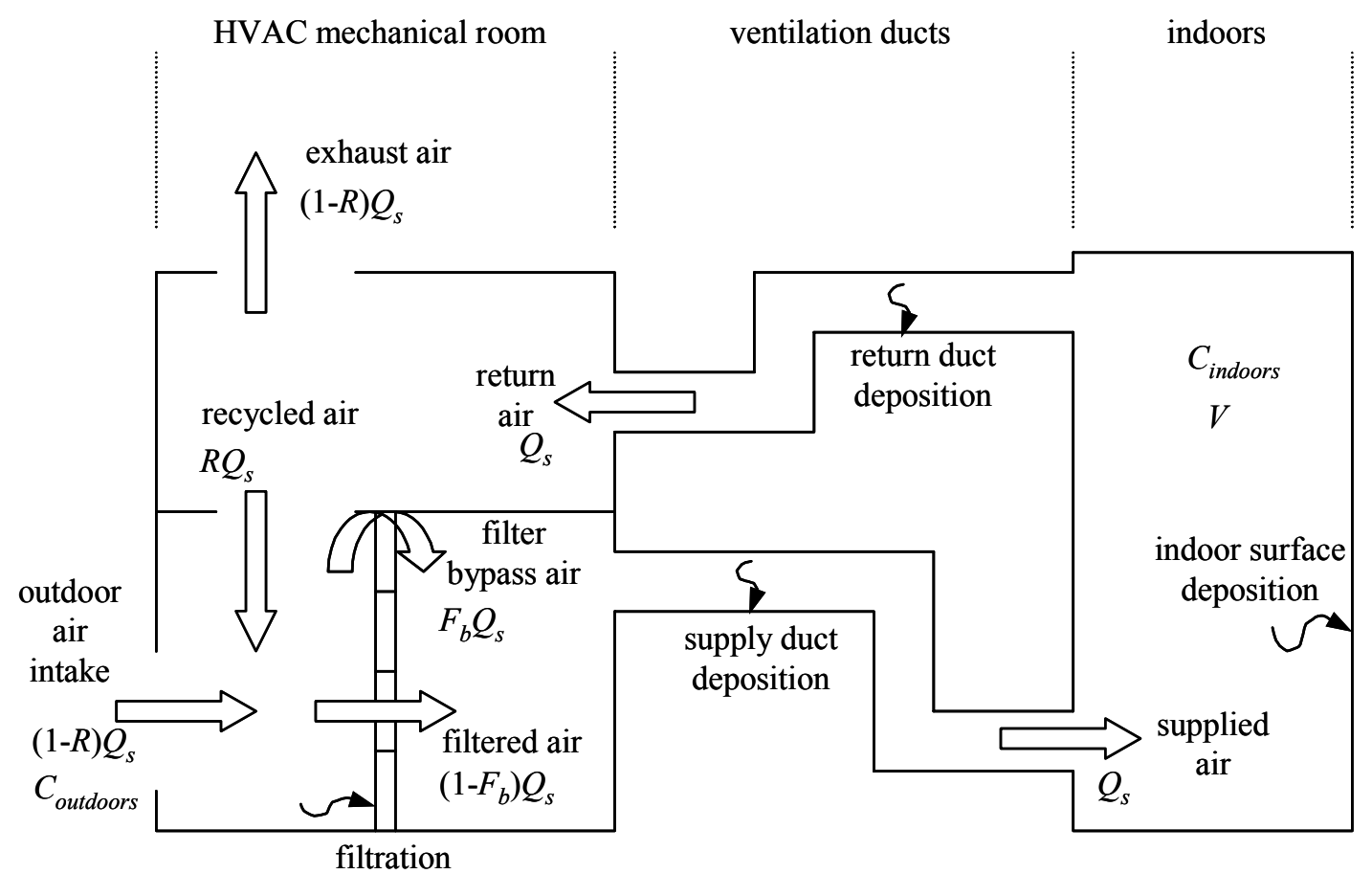

Figure 2 Schematic diagram for analysis of particle fate in a mechanically ventilated building. The block arrows indicate airflow paths; small arrows show potential particle fates.

(a) return duct runs

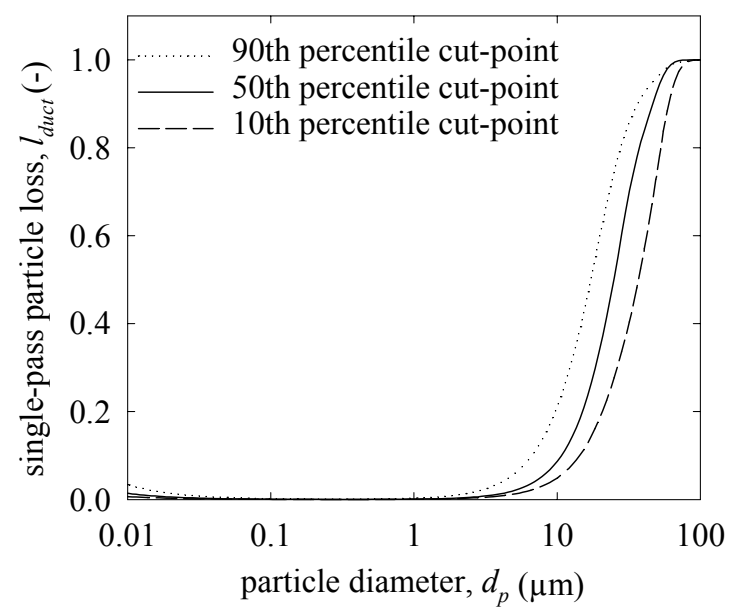

(b) supply duct runs

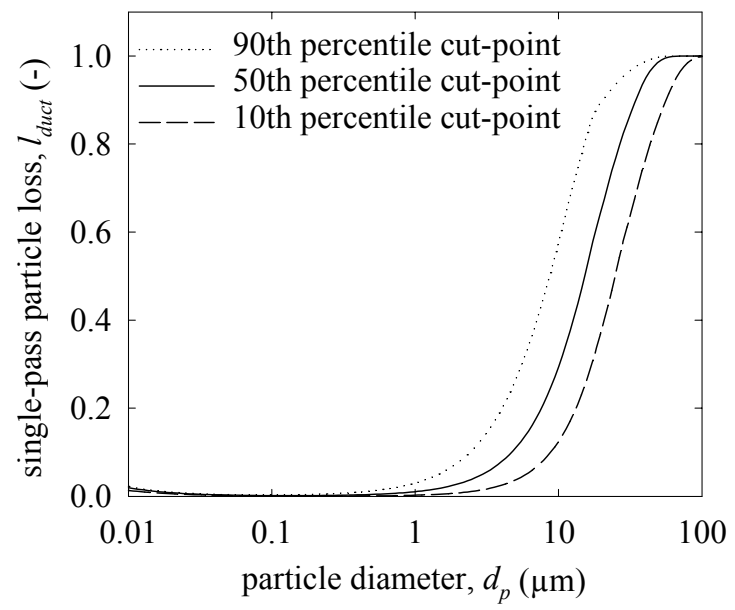

Figure 3 Predicted fractional losses for a single pass through (a) return duct runs and (b) supply duct runs. 
(a) return duct runs
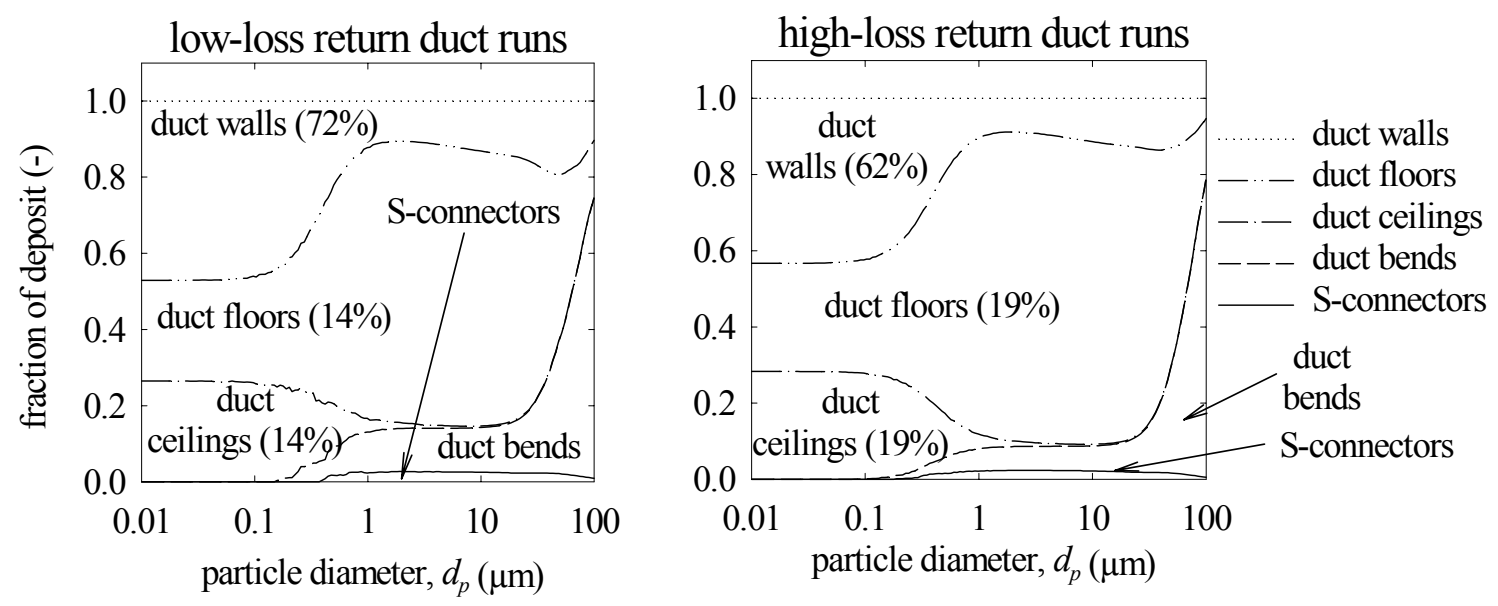

(b) supply duct runs
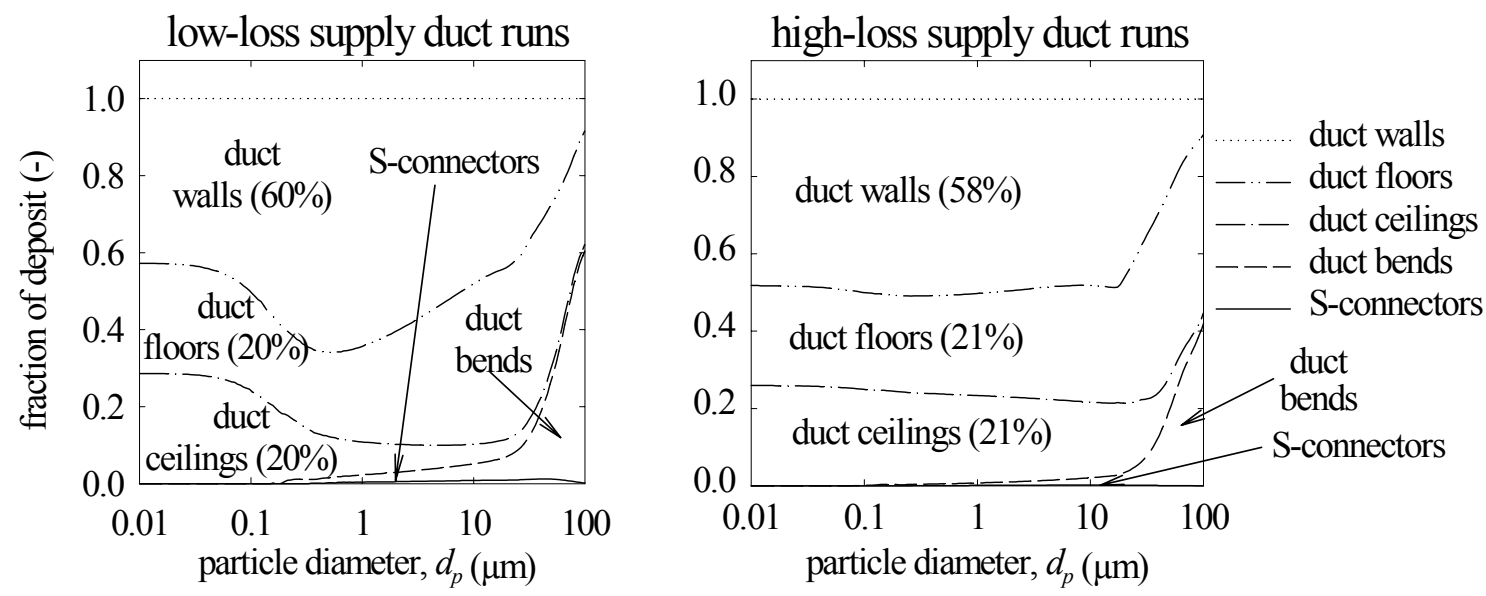

Figure 4 Fraction of total losses occurring at different duct surfaces in (a) return duct runs and (b) supply duct runs with both low and high particle losses. 
(a) return duct runs
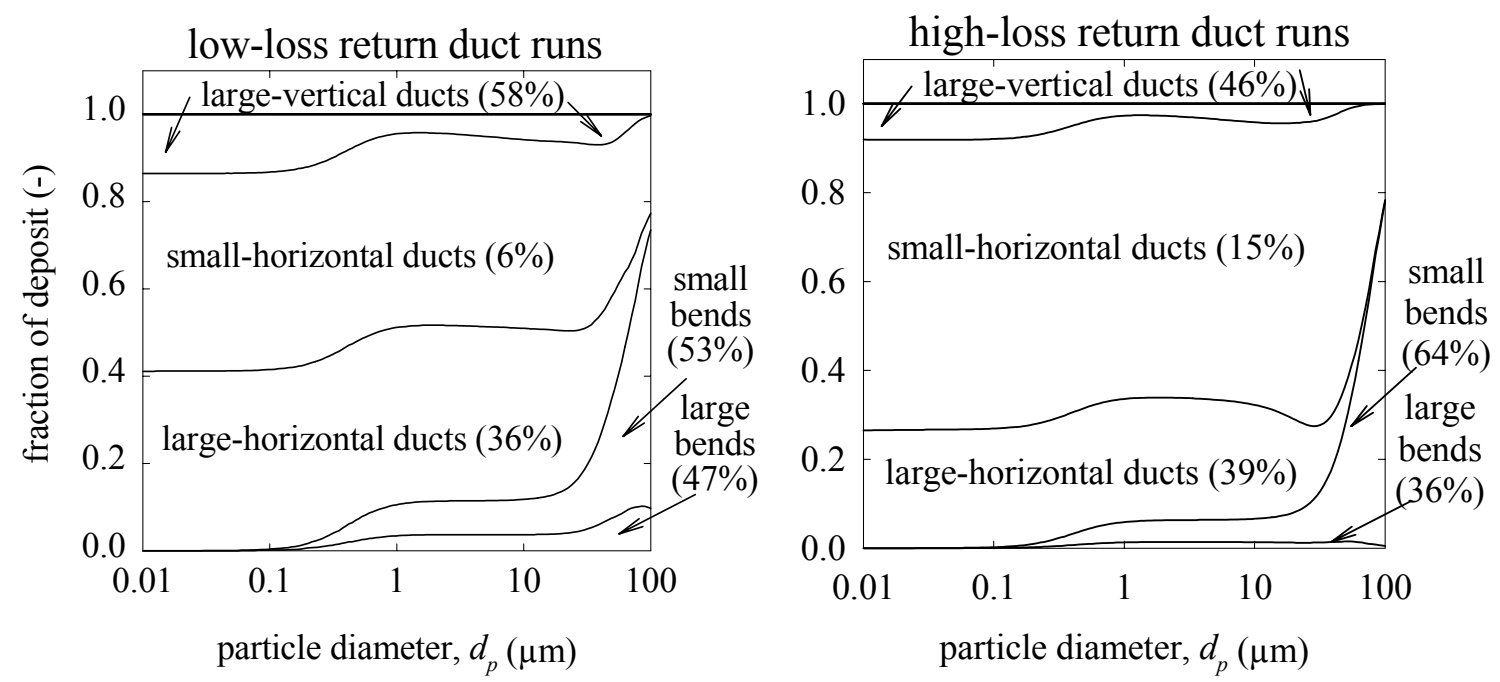

(b) supply duct runs
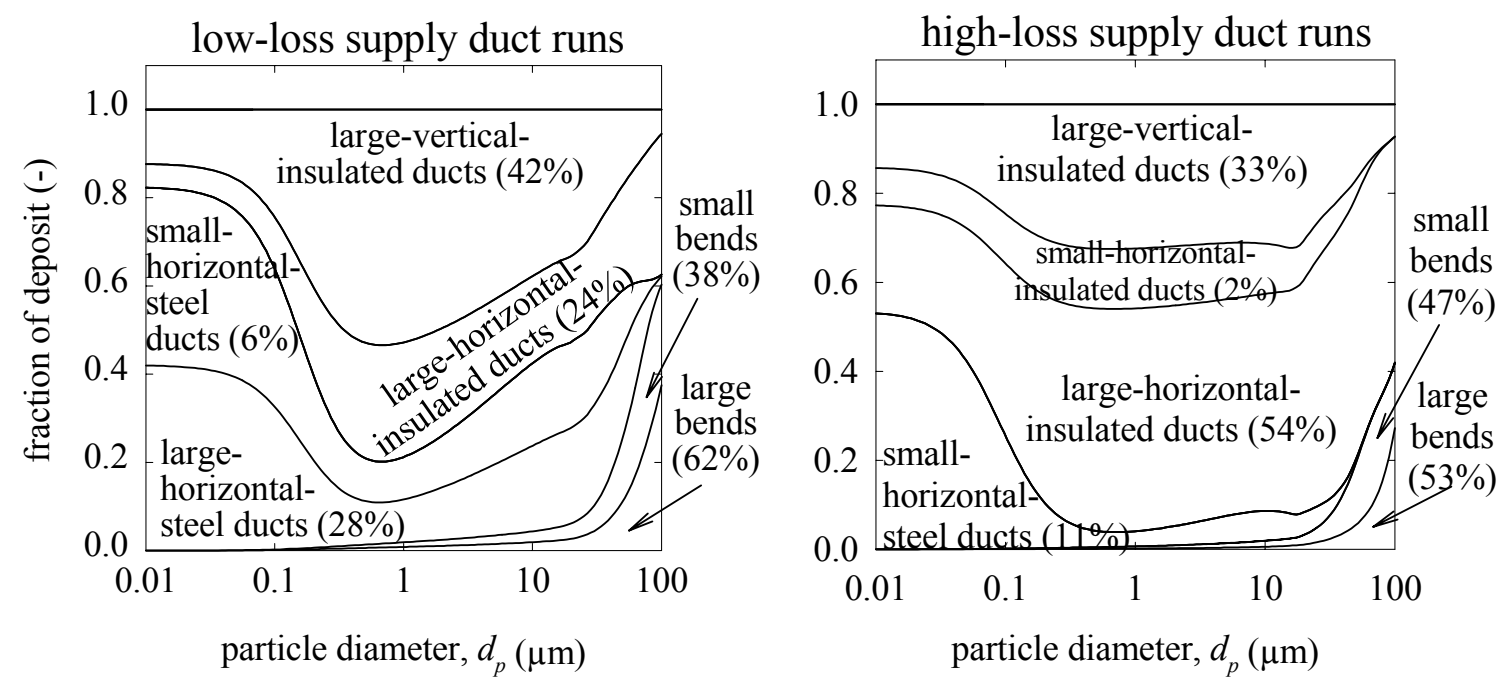

Figure 5 Fraction of total losses occurring in different duct generation classes in (a) return duct runs and (b) supply duct runs with both low and high particle losses. 
(a) no filters at air intake
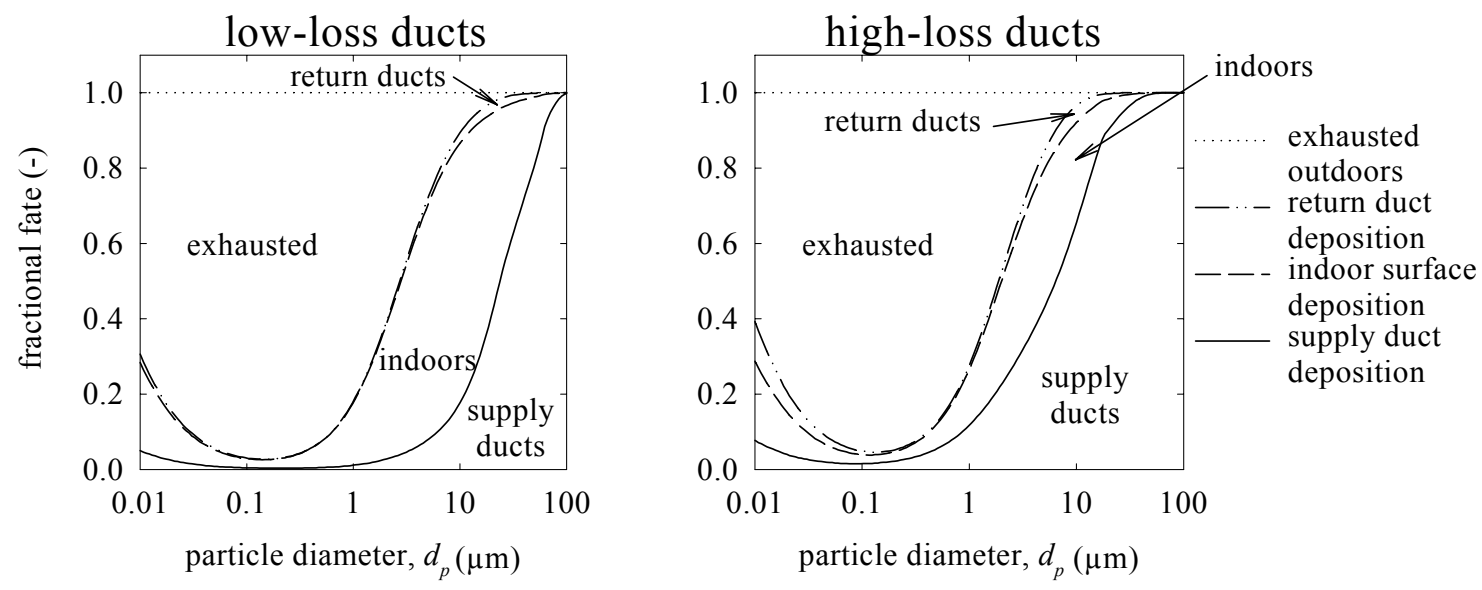

(b) $40 \%$ ASHRAE filters at air intake
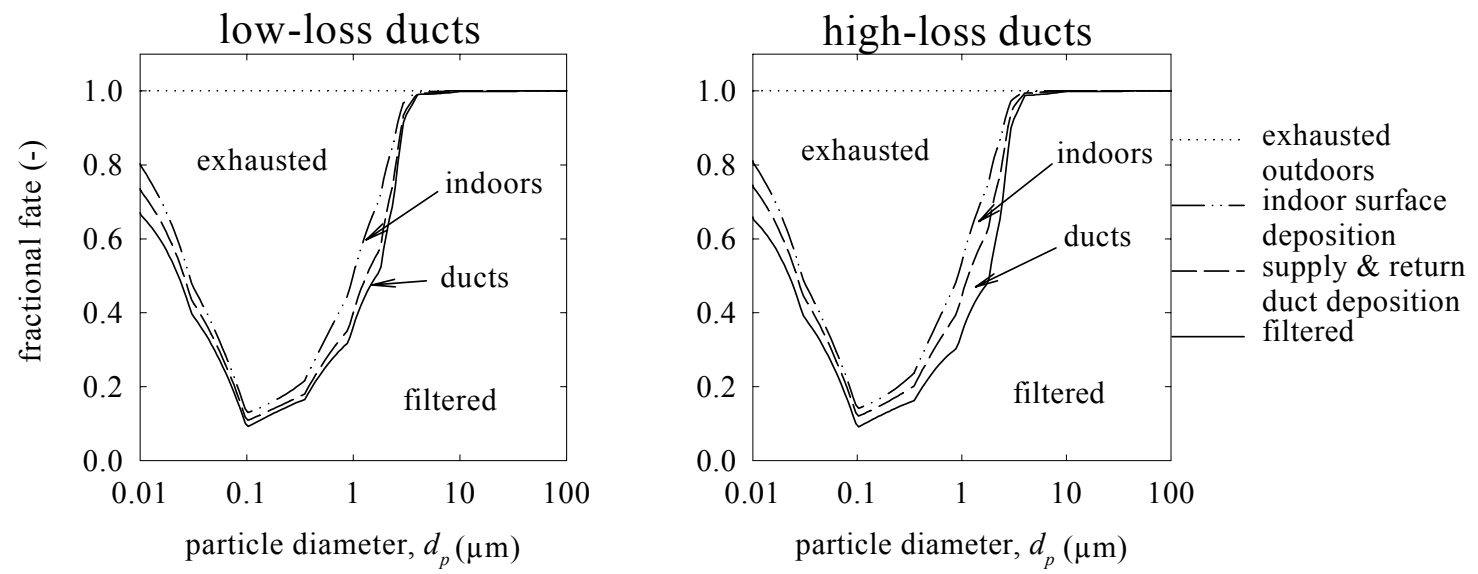

(c) $85 \%$ ASHRAE filters at air intake
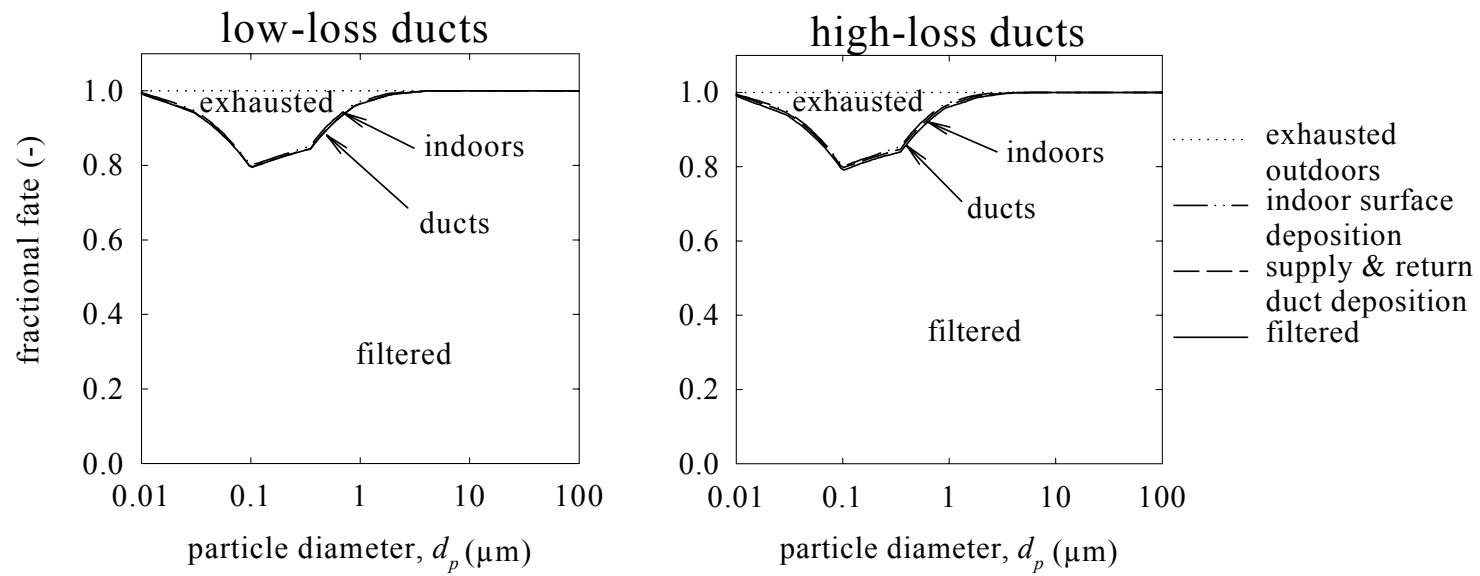

Figure 6 Predicted fractional fates of outdoor particles drawn into an air intake with (a) no filters, (b) 40\% ASHRAE filters and (c) 85\% ASHRAE filters for both low-loss and high-loss ducts. 
(a) no filters at air intake
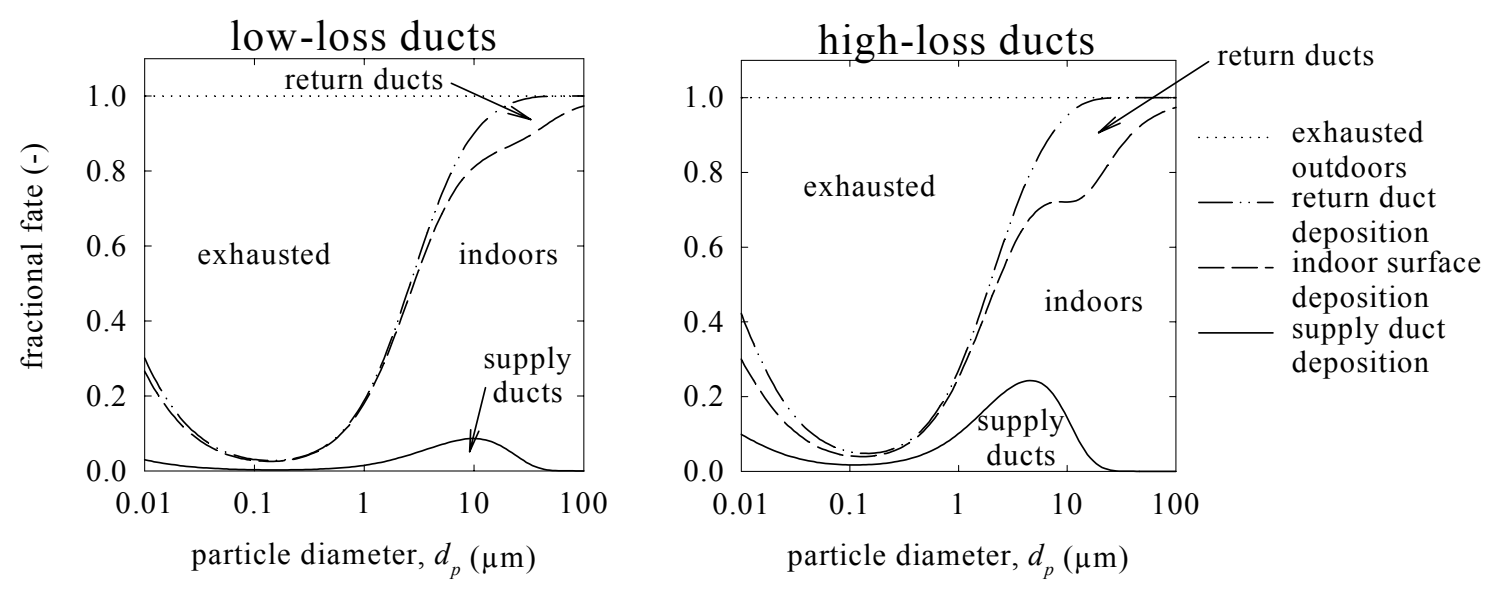

(b) $40 \%$ ASHRAE filters at air intake
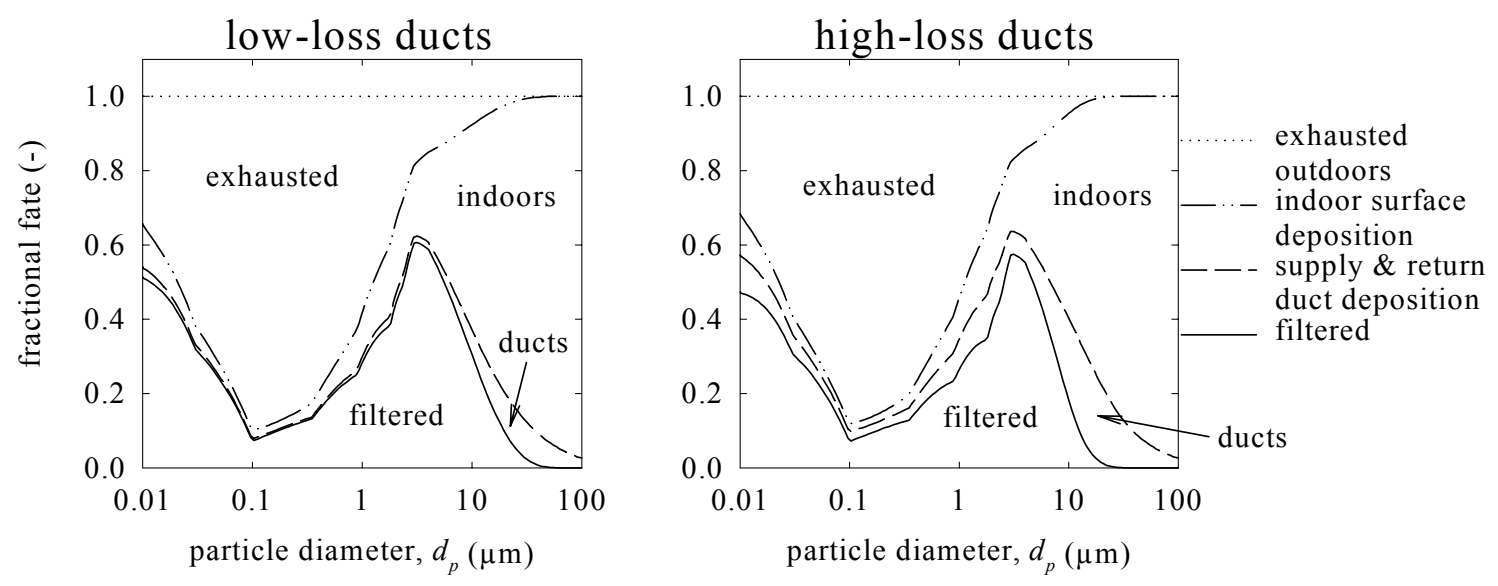

(c) $85 \%$ ASHRAE filters at air intake
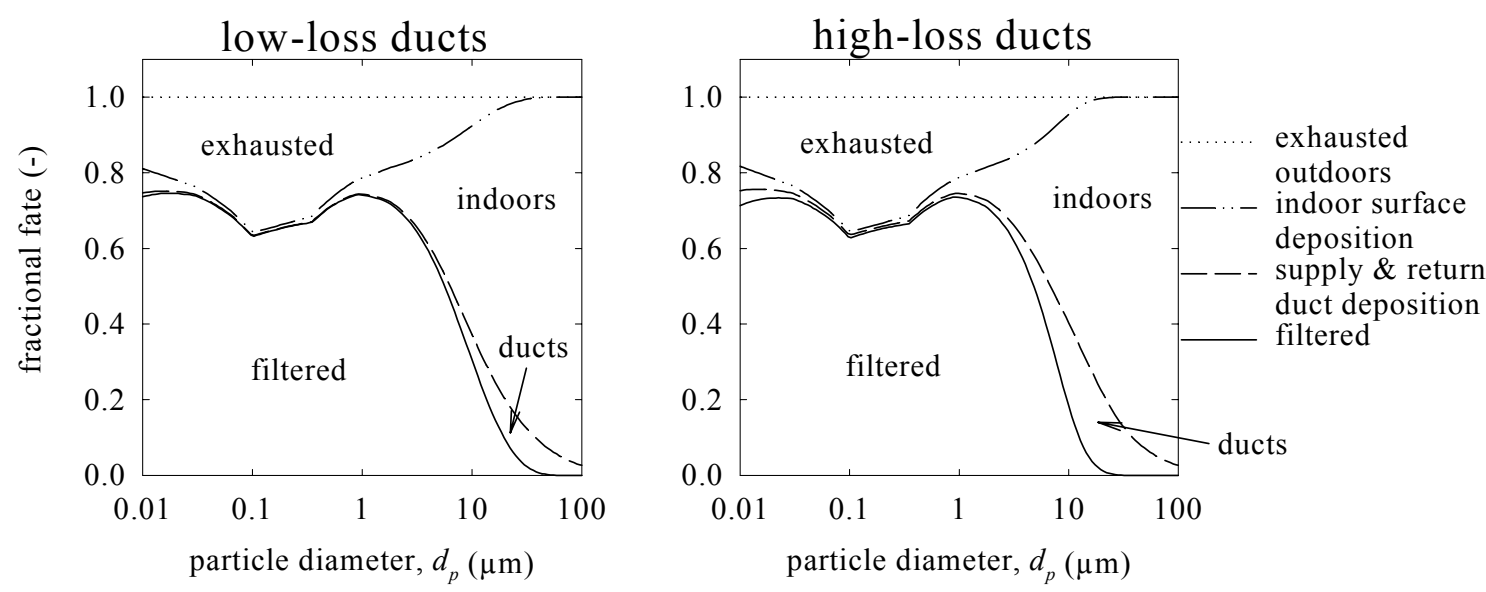

Figure 7 Predicted fractional fates of particles released in a building with (a) no filters, (b) 40\% ASHRAE filters and (c) 85\% ASHRAE filters for both low-loss and high-loss ducts. 